\title{
Efficacy Analysis of Adjuvant Chemotherapy with Gemcitabine Plus Platinum or S-I in Biliary Tract Carcinoma: A Multi-Center Retrospective Study
}

This article was published in the following Dove Press journal: Cancer Management and Research

\begin{abstract}
Huan Gao,' Tao Tian, (iD) Suoni $\mathrm{Li}^{2}$ Yinbin Zhang, (D) ${ }^{3}$ Xiao Fu,' Xiaoqiang Zheng, (D) ' Na Liu, (D) 'Aimin Jiang, (D) Mengdi Ren,' Xiaoni Zhang,' Xuan Liang,' Zhiping Ruan, (iD ' Zhimin Geng, ${ }^{4, *}$ Yu Yao ${ }^{1, *}$

'Department of Medical Oncology, The First Affiliated Hospital of Xi'an Jiaotong University, Xi'an, People's Republic of China; ${ }^{2}$ Department of Medical Oncology, Tumor Hospital of Shaanxi, Xi'an, People's Republic of China; ${ }^{3}$ Department of Oncology, The Second Affiliated Hospital of Xi'an Jiaotong University, Xi'an, People's Republic of China; ${ }^{4}$ Department of Hepatobiliary Surgery, The First Affiliated Hospital of Xi'an Jiaotong University, Xi'an, People's Republic of China
\end{abstract}

*These authors contributed equally to this work
Purpose: Biliary tract cancers (BTCs) have a poor overall prognosis, as patients who underwent curative surgery frequently experience disease recurrence. At present, there is a paucity of well-documented adjuvant chemotherapy regimen. This study aimed to assess whether gemcitabine plus platinum or S-1 adjuvant chemotherapy have different impact on relapse-free survival (RFS).

Patients and Methods: We selected patients undergoing radical biliary tract cancer surgery, pathologically confirmed adenocarcinoma and received gemcitabine plus platinum (cisplatin or oxaliplatin) or S-1 adjuvant chemotherapy from September 2013 to May 2020. The primary study endpoint was RFS. The secondary endpoint was safety.

Results: Overall 136 patients were enrolled. The median follow-up was 32.3 months and the median RFS was 17.0 months (95\% CI 8.9-25.1). The median RFS was 14.1 months (95\% CI 6.7-21.5) in gemcitabine plus platinum group and 33.0 months (95\% CI 9.3-56.7) in gemcitabine plus S-1 (GS) group, a non-significant difference both in univariate $(\mathrm{P}=0.092)$ and in multivariate analysis $(\mathrm{P}=0.058)$. Lymph node status $(\mathrm{N}-\mathrm{vs} \mathrm{N}+\mathrm{HR}=0.477,95 \% \mathrm{CI} 0.285-0.799$; $\mathrm{P}=0.005$ ) and chemotherapy cycles ( $<6$ vs $6-8: \mathrm{HR}=1.828,95 \% \mathrm{CI} 1.117-2.993 ; \mathrm{P}=0.016$ ) were independent impact factors for RFS. GS group had lower incidence of adverse reactions.

Conclusion: Compared with gemcitabine plus platinum, GS regimen has a tendency to obtain longer RFS (although there is no statistically significant difference) and less toxic. GS regimen has the potential to be investigated as a standard regimen for adjuvant chemotherapy.

Keywords: biliary tract cancer, adjuvant chemotherapy, gemcitabine, platinum, S-1

\section{Introduction}

Biliary tract cancers (BTCs) include intrahepatic cholangiocarcinomas (iCCAs), hilar cholangiocarcinomas (hCCAs), distal cholangiocarcinomas (dCCAs) and gallbladder carcinomas (GBCs). Although the incidence of BTCs is relatively low, it has shown an upward trend in recent years. In 2019, approximately 12,360 patients with new biliary system tumors were diagnosed in the United States and 3,960 died. ${ }^{1}$ Cancer statistics in China in 2015 were even grimmer, with about 52,800 new cases of GBCs and 40,700 deaths. ${ }^{2}$ BTCs have a poor overall prognosis, and surgery is the only curable means. However, for those who have had curative surgical resection also experience a recurrence, the 5-year overall survival rate is only approximately $20 \%,{ }^{3}$ suggesting adjuvant chemotherapy plays an important role in the treatment of BTCs.

Zhimin Geng

Department of Hepatobiliary Surgery

The First Affiliated Hospital of Xi'an

jiaotong University, No. 277 Yanta West

Road, Xi'an, Shaanxi 7I006I, People's

Republic of China

Tel/Fax +86-29-85323893

Email gengzhimin@mail.xjtu.edu.cn 
In advanced BTCs, ABC-02 study laid the foundation for gemcitabine plus cisplatin (GP) as the standard regimen for first-line chemotherapy, ${ }^{4}$ indicating BTCs is a chemotherapy-sensitive malignant tumor and GP regimen has good anticancer activity for biliary system tumors. Some studies showed that the combination of gemcitabine and oxaliplatin (GEMOX) has good activity in advanced $\mathrm{BTCs}^{5-8}$ and GEMOX was used as the matched group in randomized trials in patients who could not be resected. ${ }^{9-12}$ A Phase III trial (JCOG1113) demonstrated gemcitabine plus S-1 (GS) combination therapy is noninferior to gemcitabine plus cisplatin combination therapy in advanced BTCs (median overall survival [mOS]: 13.4 months in GP vs 15.1 months in GS, HR 0.95; 90\% CI 0.78-1.15; $\mathrm{P}=0.046) .{ }^{13}$ Another randomized phase III study compared gemcitabine, cisplatin and S-1 (GCS) to gemcitabine and cisplatin at first-line chemotherapy, suggested GCS could be considered a new standard treatment (mOS: 13.5 months in GCS vs 12.6 months in GP, HR 0.79; 95\% CI 0.60-1.04; $\mathrm{P}=0.046){ }^{14}$

Due to the low incidence and few clinical studies, there is a paucity of well-documented adjuvant chemotherapy regimen. A meta-analysis showed a potential benefit of adjuvant chemotherapy in patients with BTCs, especially in the patients with positive lymph nodes. ${ }^{3}$ Therefore, the researchers tried to apply the first-line regimens to adjuvant settings. It has been proved in a phase II study that adjuvant chemotherapy with gemcitabine with or without cisplatin was well tolerated and resulted in promising survival of the patients. ${ }^{15}$ However, the BCAT clinical trial in Japan showed no significant difference in overall survival (OS) and relapse-free survival (RFS) between gemcitabine group and observation group. ${ }^{16}$ Another phase III trial compared adjuvant GEMOX regimen with surveillance in resected biliary tract cancer, the result showing no significant difference. ${ }^{17}$ Capecitabine has shown positive results in BILCAP clinical studies, ${ }^{18}$ and S-1, also a precursor of fluorouracil, has been shown to be effective in a variety of tumor species. In the KHBO-1208 Phase II clinical trial, the efficacy of S-1 in adjuvant chemotherapy for biliary cancer was demonstrated to be superior to gemcitabine alone. ${ }^{19}$

The ACTICCA-1 study is a Phase III, randomized, multicenter clinical study comparing gemcitabine and cisplatin to capecitabine after curative intent resection of cholangiocarcinoma and muscle invasive GBCs. ${ }^{20}$ The results of the study are yet to be published. Researchers are exploring adjuvant chemotherapy for biliary tract cancer, but at present, there are few evidence-based adjuvant chemotherapy regimens and studies. This study was aimed to assess whether gemcitabine plus platinum or S-1 adjuvant chemotherapy have different efficiency in RFS.

\section{Patients and Methods}

This retrospective study reviewed the records of patients who underwent curative resection of BTCs in the First Affiliated Hospital of Xi'an Jiaotong University, the Second Affiliated Hospital of Xi' an Jiaotong University and Tumor Hospital of Shaanxi (Shaanxi Province, China) from September 2013 to May 2020. All patients had histologically confirmed gallbladder or bile duct adenocarcinoma, and were treated with GP, GEMOX or GS adjuvant chemotherapy during the study period. None of the enrolled patients had received prior anticancer treatment. Collected relevant clinicopathological information including age, gender, Eastern Cooperative Oncology Group performance status (ECOG PS), comorbidity, tumor site, TNM-stage, T stage, lymph node involvement, pathological differentiation, chemotherapy regimens and chemotherapy cycles. Comorbidity was defined as having one or more diseases listed in the Charlson Comorbidity Index. Gemcitabine was given through intravenous drip at $1000 \mathrm{mg} / \mathrm{m} 2$ on day 1 and 8 . Cisplatin was given through intravenous injection at $25 \mathrm{mg} / \mathrm{m} 2$ for consecutive 3 days or $75 \mathrm{mg} / \mathrm{m} 2$ on day 1 . Oxaliplatin was given through intravenous drip at $130 \mathrm{mg} / \mathrm{m} 2$ on day 1 . S-1 was administered orally at a dose of $80 \mathrm{mg} / \mathrm{m} 2 / \mathrm{d}$ for continuous 14 days, followed by a 1-week rest period. Treatment was repeated every 3 weeks. All patients received at most 8 chemotherapy cycles until disease progression, unacceptable toxicity or other patient rejection.

Imaging examination, computerized tomography (CT), was performed every 2 cycles. Serum tumor markers were measured at baseline and every 1-2 cycle. CA19-9 normal reference range was $0-39 \mathrm{U} / \mathrm{mL}$. We took the average of CA19-9 multiples of change after 2 cycles of chemotherapy as the cut-off value. The primary endpoint of the study was RFS, defined by the time from surgery to recurrence (local or distant) or death from any cause. Adverse events were graded according to the National Cancer Institute Common Terminology Criteria for Adverse Events (NCICTCAE) version 3.0. To increase the completeness of information, adverse reactions were obtained from medical records, laboratory tests during treatment and follow up.

\section{Statistical Analysis}

All statistical analysis was performed by using SPSS 18.0 software. Baseline characteristics were counted by descriptive analysis. The Chi-square test was utilized to compare the 
distribution between groups, the Kaplan-Meier method was used for univariate analysis, Cox regression model was used for multivariate analysis. GraphPad Prism 5.0 software was used to draw survival curve, to investigate the relationship between clinicopathological data and RFS. Subgroup analysis was conducted to investigate whether there are significant differences between different chemotherapy regimens in subgroups with different characteristic. $\mathrm{P}<0.05$ was considered statistically significant.

\section{Results}

\section{Patient Characteristics}

A total of 893 patients were screened, and 136 patients were finally enrolled (Figure 1). Patients' characteristics were evenly distributed between the study groups (Table 1). The median age of patients was 58 (range 32-74) years. Male and female patients accounted for $33 \%$ and $67 \%$ respectively. The majority of the tumors were gallbladder cancer (58\%) and $71 \%$ were at the stage of T3 and T4. $35 \%$ of patients were accompanied by other underlying diseases and 36\% were lymph node involvement. All patients had a ECOG PS score of $0-1$. There were 81 patients in GP/GEMOX group and 55 in GS group respectively. The median of chemotherapy cycles patients received was 5 cycles. Due to the incompleteness of laboratory data, we analyzed the serum CA19-9 levels of 55 patients with complete data. The initial median serum CA19-9 level was $14.7 \mathrm{U} / \mathrm{mL}$ (range $0.6-430.7 \mathrm{U} / \mathrm{mL}$ ).

\section{Survival}

With a median follow-up of 32.3 months, the median RFS was 17.0 months (95\% CI 8.9-25.1) and the median OS was 30.8

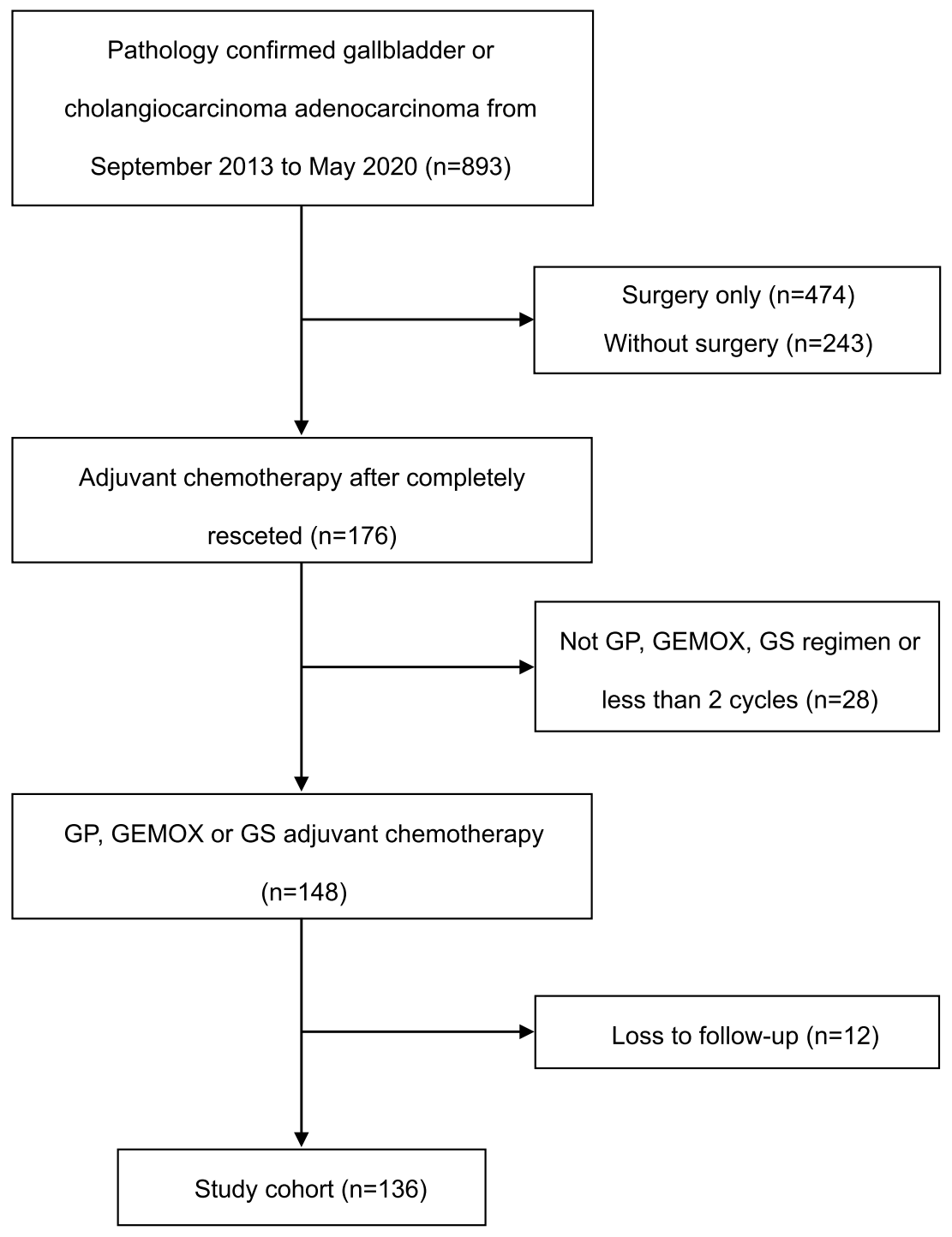

Figure I Flow chart of patient enrolment. 
Table I Clinicopathological Characteristics of 136 Patients Enrolled

\begin{tabular}{|c|c|c|c|}
\hline $\begin{array}{l}\text { Clinicopathological } \\
\text { Features }\end{array}$ & $\begin{array}{l}\text { GP/GEMOX } \\
(n=8 I)\end{array}$ & $\begin{array}{l}\text { GS } \\
(n=55)\end{array}$ & $P$ value \\
\hline $\begin{array}{l}\text { Gender } \\
\text { Male } \\
\text { Female }\end{array}$ & $\begin{array}{l}27(33 \%) \\
54(67 \%)\end{array}$ & $\begin{array}{l}18(33 \%) \\
37(67 \%)\end{array}$ & $0.94 I$ \\
\hline $\begin{array}{l}\text { Age } \\
\quad \leq 58 \\
>58 \\
>65 *\end{array}$ & $\begin{array}{l}42(52 \%) \\
39(48 \%) \\
9(11 \%)\end{array}$ & $\begin{array}{l}26(47 \%) \\
29(53 \%) \\
I I(20 \%)\end{array}$ & $\begin{array}{l}0.600 \\
0.151\end{array}$ \\
\hline $\begin{array}{c}\text { ECOG PS } \\
0 \\
1\end{array}$ & $\begin{array}{l}33(41 \%) \\
48(59 \%)\end{array}$ & $\begin{array}{l}18(33 \%) \\
37(67 \%)\end{array}$ & 0.343 \\
\hline $\begin{array}{l}\text { Comorbidity } \\
\text { No } \\
\text { Yes }\end{array}$ & $\begin{array}{l}54(67 \%) \\
27(33 \%)\end{array}$ & $\begin{array}{l}34(62 \%) \\
21(38 \%)\end{array}$ & $0.56 \mathrm{I}$ \\
\hline $\begin{array}{l}\text { Tumor site } \\
\text { Gallbladder } \\
\text { Bile duct }\end{array}$ & $\begin{array}{l}46(57 \%) \\
35(43 \%)\end{array}$ & $\begin{array}{l}33(60 \%) \\
22(40 \%)\end{array}$ & 0.710 \\
\hline $\begin{array}{l}\text { TNM-stage } \\
\text { I-II } \\
\text { III-IVA }\end{array}$ & $\begin{array}{l}30(37 \%) \\
51(63 \%)\end{array}$ & $\begin{array}{l}17(31 \%) \\
38(69 \%)\end{array}$ & 0.461 \\
\hline $\begin{array}{r}\text { T-stage } \\
\text { TI-T2 } \\
\text { T3-T4 }\end{array}$ & $\begin{array}{l}26(32 \%) \\
55(68 \%)\end{array}$ & $\begin{array}{l}13(24 \%) \\
42(76 \%)\end{array}$ & 0.284 \\
\hline $\begin{array}{l}\text { Lymph node } \\
\qquad \begin{array}{l}\mathrm{N}- \\
\mathrm{N}+\end{array}\end{array}$ & $\begin{array}{l}53(65 \%) \\
28(35 \%)\end{array}$ & $\begin{array}{l}34(62 \%) \\
21(38 \%)\end{array}$ & 0.667 \\
\hline $\begin{array}{l}\text { Pathological } \\
\text { differentiation } \\
\text { Well-moderately } \\
\text { Poor } \\
\text { Unknown }\end{array}$ & $\begin{array}{l}46(57 \%) \\
27(33 \%) \\
8(10 \%)\end{array}$ & $\begin{array}{l}32(58 \%) \\
16(29 \%) \\
7(13 \%)\end{array}$ & 0.803 \\
\hline $\begin{array}{l}\text { Chemotherapy cycles } \\
<6 \\
6-8\end{array}$ & $\begin{array}{l}42(52 \%) \\
39(48 \%)\end{array}$ & $\begin{array}{l}25(45 \%) \\
30(55 \%)\end{array}$ & 0.464 \\
\hline
\end{tabular}

Note: *Considering the toxicity of platinoids, it was also compared in elderly patients over 65 years old.

Abbreviations: ECOG PS, Eastern Cooperative Oncology Group performance status; GP, gemcitabine plus cisplatin; GEMOX, gemcitabine plus oxaliplatin; GS, gemcitabine plus $\mathrm{S}-\mathrm{I}$; $\mathrm{N}$-, lymph node negative; $\mathrm{N}+$, lymph node negative.

months (95\% CI 19.6-42.0). A total of 81 progress events occurred. The results of univariate analysis suggested that there was no significant difference in RFS according to the gender, age, ECOG PS, comorbidity, tumor site, TNM-stage, T-stage, pathological differentiation and chemotherapy regimen, while lymph node involvement $(\mathrm{P}=0.013)$ and chemotherapy cycles $(\mathrm{P}=0.036)$ were associated with RFS (shown in Table 2). In 55 patients with complete laboratory data, baseline CA19-9 levels $>39 \mathrm{U} / \mathrm{mL}(\mathrm{P}=0.001)$ and with a doubling of CA19-9 after 2 cycles chemotherapy $(\mathrm{P}=0.021)$ were associated with a shorter RFS (shown in Table 2). The median RFS was 14.1 months (95\% CI 6.7-21.5) in GP/ GEMOX group and 33.0 months $(95 \%$ CI 9.3-56.7) in GS group. The Kaplan-Meier curve is shown in Figure 2. The 1-year, 2-year and 3-year RFS rates in GS group were 68.6\%, $53.9 \%$ and $51.5 \%$, and in GP/GEMOX group were $55.7 \%$, $39.4 \%$ and $33.4 \%$. The median OS was not reached in GS group and 24.5 months in $\mathrm{GP} / \mathrm{GEMOX}$ group ( $\mathrm{P}=0.142$ ). Results of Cox multivariate analysis showed no significant difference in RFS between the two treatment groups (GS vs GP/GEMOX: HR $=0.627,95 \%$ CI $0.387-1.016, \mathrm{P}=0.058$ ). Lymph node status $(\mathrm{N}-\mathrm{vs} \mathrm{N}+$ : HR $=0.477,95 \%$ CI $0.285-$ $0.799 ; \mathrm{P}=0.005)$ and chemotherapy cycles ( $<6$ vs $6-8$ : $\mathrm{HR}=1.828,95 \%$ CI 1.117-2.993; $\mathrm{P}=0.016$ ) were independent impact factors for RFS (shown in Table 3). The Kaplan-Meier curve is shown in Figure $3 \mathrm{~A}$ and B. Considering the intersection of Kaplan-Meier Curves based on chemotherapy cycles, we performed landmark analysis. Before 38 months, the RFS of patients in 6-8 cycles group is better than that in $<6$ cycles group ( $\mathrm{P}=0.036$ ), but after 38 months, there is no significant difference between the two groups (shown in Figure 4).

\section{Exploratory Subgroup Analysis}

From the analysis, GS benefit was consistent across these cohorts: female $\quad(\mathrm{HR}=0.531, \quad 95 \%$ CI $0.288-0.979$; $\mathrm{P}=0.042)$, no comorbidity ( $\mathrm{HR}=0.389$, 95\% CI 0.188 -$0.804 ; \mathrm{P}=0.011$ ), III-IVA (HR $=0.487,95 \%$ CI $0.262-$ $0.906 ; \mathrm{P}=0.023)$ and well-moderately differentiation $(\mathrm{HR}=0.462,95 \%$ CI $0.218-0.981 ; \mathrm{P}=0.044$ ) (shown in Figure 5).

\section{Adverse Events}

Hematologic and non-hematologic adverse events of grade 3-4 are shown in Table 4. The incidence of neutropenia was $17 \%$ and thrombocytopenia was $13 \%$ in all patients with hematological toxicity. The most significant nonhematological adverse events were nausea (13\%) and vomiting (13\%). Between the two treatment groups, there were significant differences in the adverse reactions of neutropenia $(\mathrm{P}=0.013)$, nausea $(\mathrm{P}=0.041)$ and vomiting $(\mathrm{P}=0.010)$. Adverse reactions of GS group were globally lower. 
Table 2 Univariate Analysis of Clinicopathological Factors Associated with RFS

\begin{tabular}{|c|c|c|}
\hline Clinicopathological Features & $\begin{array}{l}\text { mRFS } \\
\text { (Month,95\% Cl) }\end{array}$ & $P$ value \\
\hline $\begin{array}{l}\text { Gender } \\
\text { Male } \\
\text { Female }\end{array}$ & $\begin{array}{l}21.0(8.3-33.7) \\
14.1(8.3-20.0)\end{array}$ & 0.330 \\
\hline $\begin{array}{l}\text { Age } \\
\qquad 58 \\
>58\end{array}$ & $\begin{array}{l}19.1(9.8-28.4) \\
15.6(7.5-23.7)\end{array}$ & 0.769 \\
\hline $\begin{array}{l}\text { ECOG PS } \\
0 \\
1\end{array}$ & $\begin{array}{l}26.9(11.2-42.6) \\
15.6(9.4-21.8)\end{array}$ & 0.215 \\
\hline $\begin{array}{l}\text { Comorbidity } \\
\text { No } \\
\text { Yes }\end{array}$ & $\begin{array}{l}24.3(4.7-43.9) \\
15.8(9.8-21.8)\end{array}$ & 0.254 \\
\hline $\begin{array}{l}\text { Tumor site } \\
\text { Gallbladder } \\
\text { Bile duct }\end{array}$ & $\begin{array}{l}15.9(8.8-23.0) \\
18.9(9.9-27.9)\end{array}$ & 0.945 \\
\hline $\begin{array}{l}\text { TNM-stage } \\
\text { I-II } \\
\text { III-IVA }\end{array}$ & $\begin{array}{l}26.9(6.5-47.3) \\
13.0(5.9-20.1)\end{array}$ & 0.071 \\
\hline $\begin{array}{r}\text { T-stage } \\
\text { TI-T2 } \\
\text { T3-T4 }\end{array}$ & $\begin{array}{l}37.9(15.2-60.7) \\
15.6(9.9-21.3)\end{array}$ & 0.167 \\
\hline $\begin{array}{l}\text { Lymph node } \\
\mathrm{N}- \\
\mathrm{N}+\end{array}$ & $\begin{array}{l}30.8(14.3-47.3) \\
10.8(4.9-16.7)\end{array}$ & 0.013 \\
\hline $\begin{array}{l}\text { Pathological differentiation } \\
\text { Well-moderately } \\
\text { Poor } \\
\text { Unknown }\end{array}$ & $\begin{array}{l}24.3(16.2-32.4) \\
8.7(3.5-13.9) \\
15.9(12.7-19.1)\end{array}$ & 0.471 \\
\hline $\begin{array}{l}\text { Chemotherapy cycles } \\
<6 \\
6-8\end{array}$ & $\begin{array}{l}9.5(3.9-15.1) \\
24.5(9.4-39.6)\end{array}$ & 0.036 \\
\hline $\begin{array}{l}\text { Chemotherapy regimen } \\
\text { GP/GEMOX } \\
\text { GS }\end{array}$ & $\begin{array}{l}14.1(6.7-21.5) \\
33.0(9.3-56.7)\end{array}$ & 0.092 \\
\hline $\begin{array}{l}\text { Baseline CA19-9 } \\
\quad \leq 39 \mathrm{U} / \mathrm{mL} \\
>39 \mathrm{U} / \mathrm{mL}\end{array}$ & $\begin{array}{l}19.1(16.1-22.1) \\
6.6(3.4-9.8)\end{array}$ & 0.001 \\
\hline $\begin{array}{l}\text { CA19-9 doubled after } 2 \text { cycles } \\
\text { chemotherapy } \\
\text { Yes } \\
\text { No }\end{array}$ & $\begin{array}{l}5.9(2.3-12.9) \\
19.1(15.6-22.6)\end{array}$ & 0.021 \\
\hline
\end{tabular}

Abbreviations: ECOG PS, Eastern Cooperative Oncology Group performance status; GP, gemcitabine plus cisplatin; GEMOX, gemcitabine plus oxaliplatin; GS, gemcitabine plus $\mathrm{S}-\mathrm{I} ; \mathrm{N}$-, lymph node negative; $\mathrm{N}+$, lymph node negative; mRFS, median relapse-free survival.

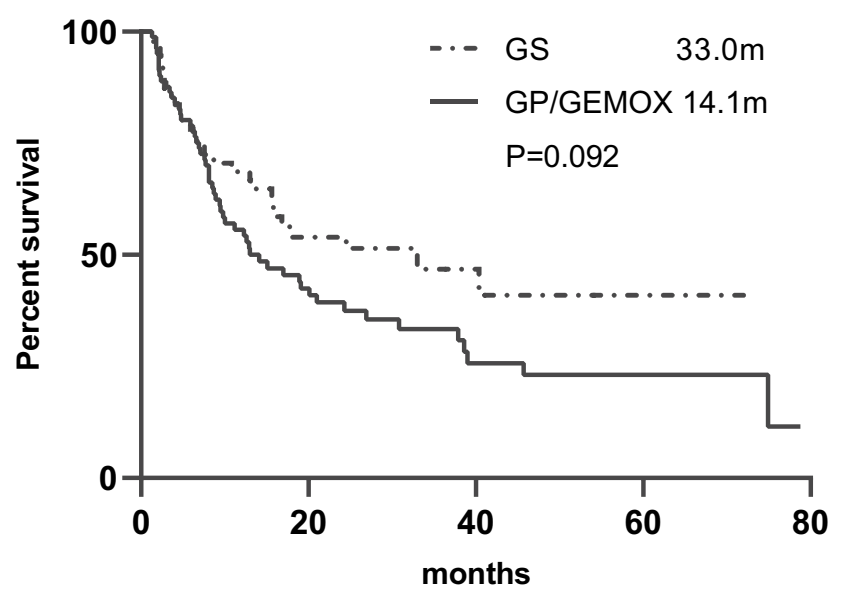

Figure 2 Kaplan-Meier Curves of RFS based on chemotherapy regime. Abbreviations: GP, gemcitabine plus cisplatin; GEMOX, gemcitabine plus oxaliplatin; GS, gemcitabine plus S-I; RFS, relapse-free survival.

\section{Discussion}

A clinical study showed that patients with postoperative adjuvant chemotherapy do not benefit from survival compared with simple surgery in BTCs. ${ }^{17}$ However, there are also studies suggesting that adjuvant chemotherapy can benefit patients with GBC after operation. ${ }^{21,22}$ The reasons for the inconsistency in the results of the above clinical studies may be that the incidence of biliary tract tumors is low, the inclusion of patients is insufficient, or there is a difference in the efficacy of the treatment plan itself. On the whole, we have reason to believe that adjuvant chemotherapy plays a vital role in BTCs.

National Comprehensive Cancer Network (NCCN) guidelines recommend fluoropyrimidines-based chemotherapy. Based on BILCAP study, American Society of clinical Oncology (ASCO) guidelines recommend capecitabine as an adjuvant chemotherapy regimen in BTCs. ${ }^{18,23} \mathrm{~S}-1$, also as a fluorouracil drug, has been fully tried in BTCs treatment, such as JCOG-1113, KHBO-1208 and KHBO-1401 studies. ${ }^{13,14,19}$ In addition, the feasibility and safety of gemcitabine combined with platinum adjuvant chemotherapy in the treatment of BTCs have been confirmed by a number of studies. ${ }^{24-28}$ These studies suggest that gemcitabine-based adjuvant chemotherapy can benefit patients. Based on experience at first-line treatment, previous retrospective study data and small sample clinical trials, European Society for Medical Oncology (ESMO) clinical practice guidelines suggest that gemcitabine-based adjuvant chemotherapy regimen were 
Table 3 Multivariate Cox Proportional Hazards Model of RFS

\begin{tabular}{|l|l|l|l|l|}
\hline Variables & & HR & $95 \%$ CI & P value \\
\hline Gender & Male vs female & 0.764 & $0.44 I-1.323$ \\
Age & $\leq 58$ vs >58 & 1.235 & $0.755-2.020$ & 0.337 \\
ECOG PS & 0 vs I & 0.675 & $0.40 I-I .134$ & $0.40 I$ \\
Comorbidity & No vs yes & 0.870 & $0.540-1.402$ & 0.137 \\
Tumor site & Gallbladder vs bile duct & 0.914 & $0.543-1.538$ \\
TNM-stage & I-II vs III-IVA & 1.149 & $0.565-2.334$ & 0.567 \\
T-stage & TI-T2 vs T3-T4 & 0.650 & $0.364-1.159$ & 0.735 \\
Lymph node & N- vs N+ & 0.477 & $0.285-0.799$ \\
\hline Pathological differentiation & Poor vs well-moderately & 1.167 & $0.698-1.952$ & 0.145 \\
& Unknown vs well-moderately & 1.075 & $0.487-2.374$ \\
\hline Chemotherapy regimen & Unknown vs poor & 1.086 & $0.468-2.519$ \\
Chemotherapy cycles & GS vs GP/GEMOX & 0.627 & 0.005 \\
\hline
\end{tabular}

Abbreviations: ECOG PS, Eastern Cooperative Oncology Group performance status; GP, gemcitabine plus cisplatin; GEMOX, gemcitabine plus oxaliplatin; GS, gemcitabine plus S-I; $\mathrm{N}$-, lymph node negative; $\mathrm{N}+$, lymph node negative; RFS, relapse-free survival.

optional. $^{29}$ We look forward to the results of the ACTICCA-1 study which compared gemcitabine plus cisplatin to capecitabine after curative intent resection of cholangiocarcinoma and muscle invasive GBCs.

This real-world study compared the efficacy of gemcitabine combined with platinum or S-1 in BTCs adjuvant chemotherapy. The median RFS of patients treated with GP/GEMOX and GS regimen were 14.1 months and 33.0 months, respectively. Although the RFS between the two treatment groups has not been statistically significant, we have seen a clear trend. $P$ values were very near to 0.05 in both univariate $(\mathrm{P}=0.092)$ and multivariate analysis $(\mathrm{P}=0.058)$, and the magnitude of the effect was considerable (with large deltas between the median RFS, as well as a promising $\mathrm{HR}$ of 0.627 ). This finding has also been reported in first-line chemotherapy. ${ }^{13,30}$ During the followup, we found that the patients with GS regimen had higher compliance, which may be related to the simplicity of treatment, lower adverse reactions and an intrinsic higher efficacy of S-1, so these patients could receive more cycles of treatment. The differences could not be observed may be owing to low numerosity. Patients with ECOG PS=0 were $1 / 3$ in GS group and more than $40 \%$ in GP/GEMOXtreated group. Higher $\mathrm{T}$ stage appeared more frequently in GP/GEMOX group. Probably, a larger sample size would have shown as a statistically significant important benefit. In addition, multivariate analysis showed that chemotherapy cycle was an independent impact factor of RFS, but

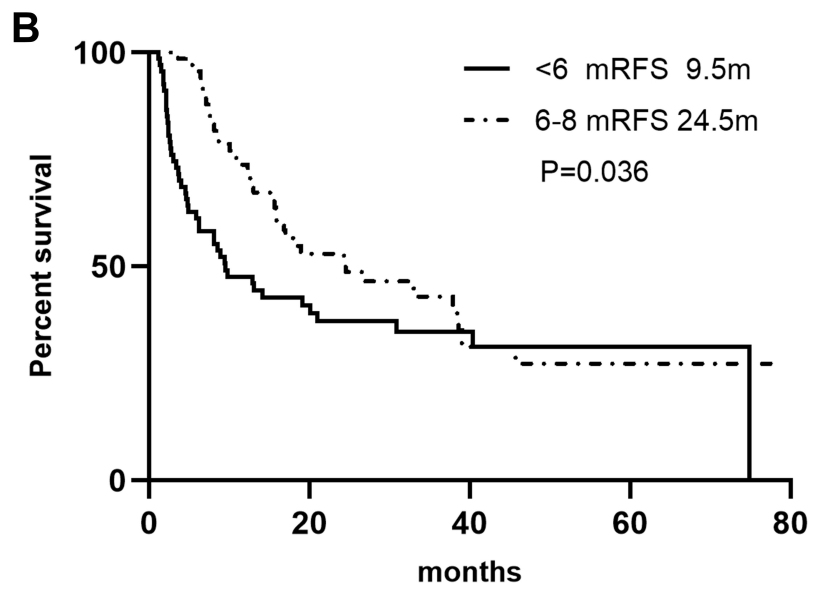

Figure 3 Kaplan-Meier Curves of RFS based on lymph node involvement (A) and chemotherapy cycles (B). Abbreviations: $\mathrm{N}$-, lymph node negative; $\mathrm{N}+$, lymph node negative; RFS, relapse-free survival. 

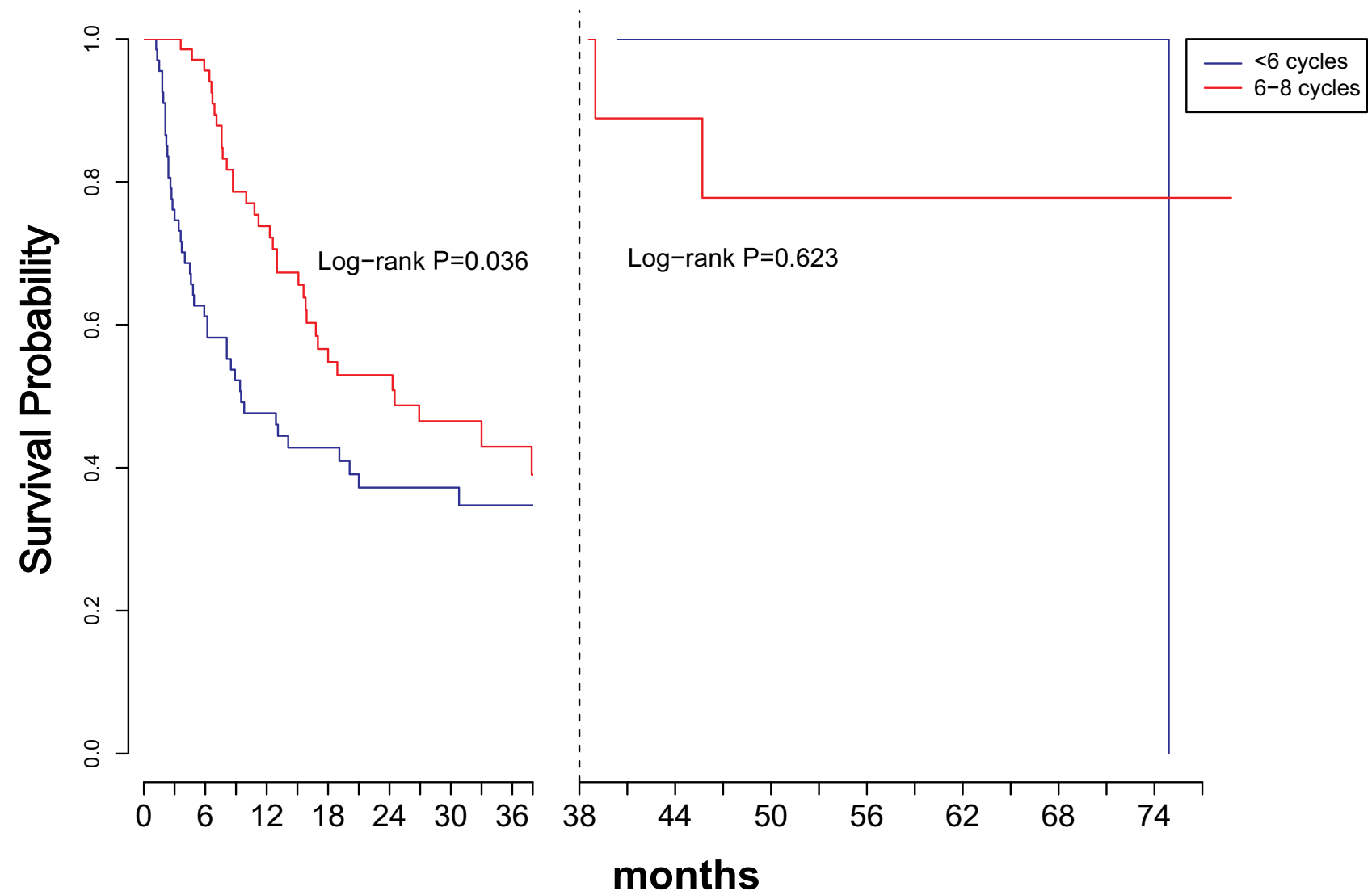

Figure 4 Landmark analysis based on chemotherapy cycles.

because of the intersection of KM curves, we performed landmark analysis. The results showed that there was significant difference between the two treatment groups before 38 months, but no significant difference after 38 months. The main reason is that the follow-up time and the number of progress events are insufficient. Prolonging the follow-up time may lead to more meaningful results. Studies have shown that the molecular biological basis of ICCs may be specific. ${ }^{31}$ However, in view of the small sample size of ICCAs and hCCAs, we just divided all patients into GBCs group and cholangiocarcinomas group. In subgroup analysis, it was observed that GS regimen had better RFS in specific subgroups. According to different circumstances, such as age, economic status and convenience of hospitalization, there may have been intentional choices in the formulation of the treatment plan, which our retrospective analysis failed to capture. These differences may have contributed to the benefit of GS vs GEMOX/GP in the study population and in the subgroups.

CA19-9 is the most commonly used tumor marker of biliary system in clinics. Some studies have pointed out that baseline CA19-9 level greater than $100 \mathrm{IU} / \mathrm{mL}$ is an important prognostic factor in advanced biliary cancer first-line chemotherapy. ${ }^{32}$ Patients with CA19-9 decline of at least $25 \%$ had liminal higher objective response rates, median time to progression and median OS. ${ }^{32} \mathrm{We}$ found a significant difference in RFS between the patients with a baseline CA19-9 greater than the normal value (39 $\mathrm{U} / \mathrm{mL}$ ) and the patients with a CA19-9 within the normal value $(\mathrm{P}=0.001)$. Because we expect to find the rule that can be significant to the therapeutic effect and prognosis in the early tumor marker changes, we analyzed the change of CA19-9 level after 2 cycles, that is, the first time to evaluate the therapeutic effect of chemotherapy in most patients. According to the analysis results, we found that there was a significant difference in RFS between patients whose CA19-9 level increased more than one time and patients whose RFS decreased or increased less than one time after two cycles of chemotherapy (5.9 months vs 19.1 months, $\mathrm{P}=0.021$ ). However, our study is only exploratory. Only 55 patients had complete CA19-9 data before and after chemotherapy. In this part of patients, tumor located in gallbladder and different parts of the bile duct were included. 


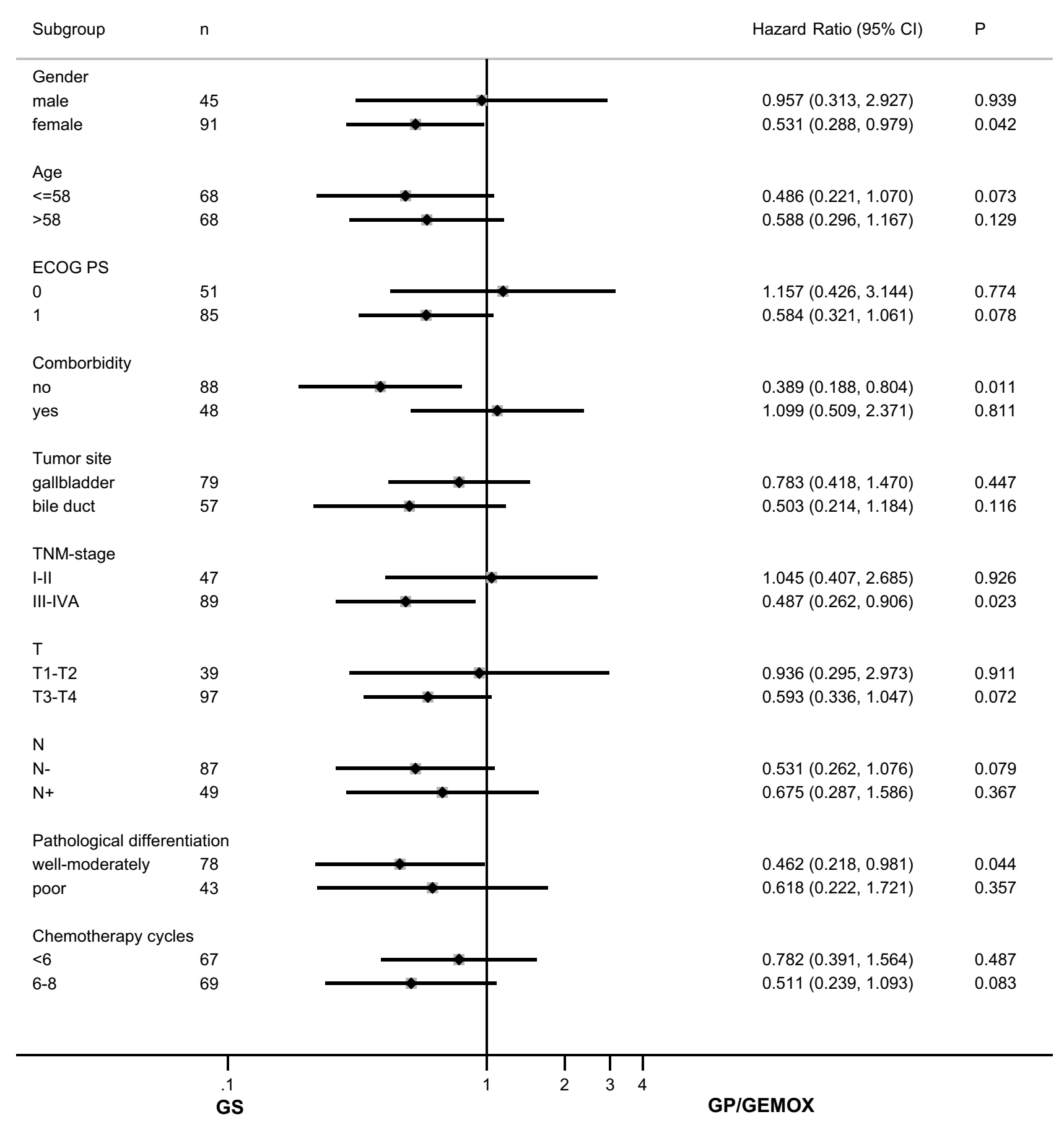

Figure 5 RFS benefits of different chemotherapy regimens in subgroups.

Abbreviations: ECOG PS, Eastern Cooperative Oncology Group performance status; GP, gemcitabine plus cisplatin; GEMOX, gemcitabine plus oxaliplatin; GS, gemcitabine plus S-I; N-, lymph node negative; $\mathrm{N}+$, lymph node negative.

The study has some limitations. First of all, all the patients in this study were Chinese patients and some of them were treated with GS chemotherapy, which is rarely used in western countries (only investigational). There are also some differences in the dosage standards of drugs. For example, in Europe, both platinoids are generally administered at doses (Cisplatin $25 \mathrm{mg} / \mathrm{m} 2$; Oxaliplatin $100 \mathrm{mg} / \mathrm{m} 2$ ), that are lower than those described in our study. This may have an impact on the comparison of toxicity. According to the results of this study and statistical parameters, the total sample size was still relatively insufficient. The trend of serum tumor markers and subgroup correlation analysis was only exploratory. Secondly, these chemotherapy regimens were commonly used in the three centers. According to the results of BILCAP study, 
Table 4 Treatment-Related Adverse Events

\begin{tabular}{|l|l|l|l|l|}
\hline Events (Grade 3-4) & $\begin{array}{l}\text { Total } \\
\text { (N/\%) }\end{array}$ & $\begin{array}{l}\text { GPI } \\
\text { GEMOX } \\
\text { (N/\%) }\end{array}$ & $\begin{array}{l}\text { GS } \\
\mathbf{( N / \% )}\end{array}$ & P value \\
\hline $\begin{array}{l}\text { Hematologic toxic effects } \\
\text { Neutropenia }\end{array}$ & $23(17 \%)$ & $19(23 \%)$ & $4(7 \%)$ & 0.013 \\
Thrombocytopenia & $17(13 \%)$ & $14(17 \%)$ & $5(9 \%)$ & 0.176 \\
Hypohemia & $11(8 \%)$ & $8(10 \%)$ & $3(5 \%)$ & 0.353 \\
\hline $\begin{array}{l}\text { Non-hematologic toxic } \\
\text { effects }\end{array}$ & & & & \\
Fatigue & $12(9 \%)$ & $9(11 \%)$ & $3(5 \%)$ & 0.240 \\
Nausea & $17(13 \%)$ & $14(17 \%)$ & $3(5 \%)$ & 0.041 \\
Vomiting & $17(13 \%)$ & $15(19 \%)$ & $2(4 \%)$ & 0.010 \\
Impaired renal function & $6(4 \%)$ & $5(6 \%)$ & $1(2 \%)$ & 0.199 \\
Infection & $2(1 \%)$ & $2(2 \%)$ & $0(0 \%)$ & 0.148 \\
Increased ALT/AST & $13(10 \%)$ & $7(9 \%)$ & $6(11 \%)$ & 0.659 \\
\hline
\end{tabular}

Abbreviations: GP, gemcitabine plus cisplatin; GEMOX, gemcitabine plus oxaliplatin; GS, gemcitabine plus S-I; ALT, alanine aminotransferase; AST, aspartate aminotransferase.

capecitabine adjuvant chemotherapy could significantly benefit the survival of patients, although the significant prolongation of survival time may be related to the inclusion of more lymph node positive patients. ${ }^{18}$ However, due to research design, we did not include capecitabine treatment in the study this time. We hope to see the comparison of capecitabine and gemcitabine combined with platinum or S-1 in future clinical studies. Finally, the overall impact of drug adjustment due to side effects also needs to be considered. In summary, this was a retrospective study, and the number of people included was limited, so a large randomized clinical trial is needed to determine the standard regimen of adjuvant chemotherapy for biliary tract carcinoma.

\section{Conclusion}

In conclusion, compared with gemcitabine plus platinum, GS regimen has a tendency to obtain longer RFS (although there is no statistically significant difference) and lower incidence of adverse reactions. GS regimen has the potential to be investigated as a standard regimen for adjuvant chemotherapy. Our study provides reference and evidence for choosing adjuvant chemotherapy regimen for biliary tract cancer in the future. More prospective clinical trials are needed to determine the standard regimen of adjuvant chemotherapy for biliary tract cancer.

\section{Ethics Approval and Consent to Participate}

This study was conducted in accordance with the Declaration of Helsinki and was approved by the ethics committee of the
First Affiliated Hospital of Xi'an Jiaotong University (NO: XJTU1AF2019LSK-067). Due to the retrospective noninterventional research design, informed consent was obtained. In addition, we confirm that the access to patients' data complied with data protection privacy laws.

\section{Acknowledgment}

The authors thank the dedicated staff of the Department of Medical Oncology and the Department of Hepatobiliary Surgery of the First Affiliated Hospital of Xi'an Jiaotong University, the Department of Oncology of the Second Affiliated Hospital of Xi'an Jiaotong University, and the Department of Medical Oncology of Tumor Hospital of Shaanxi for their valuable work.

\section{Funding}

This research received no specific grant from any funding agency in the public, commercial, or not-for-profit sectors.

\section{Disclosure}

The authors report no conflicts of interest in this work.

\section{References}

1. Siegel RL, Miller KD, Jemal A. Cancer statistics, 2019. CA Cancer J Clin. 2019;69(1):7-34. doi:10.3322/caac.21551

2. Chen W, Zheng R, Baade PD, et al. Cancer statistics in China, 2015. CA Cancer J Clin. 2016;66(2):115-132. doi:10.3322/caac.21338

3. Horgan AM, Amir E, Walter T, Knox JJ. Adjuvant therapy in the treatment of biliary tract cancer: a systematic review and meta-analysis. J Clin Oncol. 2012;30(16):1934-1940. doi:10.1200/ JCO.2011.40.5381

4. Valle J, Wasan H, Palmer DH, et al. Cisplatin plus gemcitabine versus gemcitabine for biliary tract cancer. $N$ Engl J Med. 2010;362 (14):1273-1281. doi:10.1056/NEJMoa0908721

5. André T, Reyes-Vidal JM, Fartoux L, et al. Gemcitabine and oxaliplatin in advanced biliary tract carcinoma: a phase II study. $\mathrm{Br}$ $J$ Cancer. 2008;99(6):862-867. doi:10.1038/sj.bjc.6604628

6. Harder J, Riecken B, Kummer O, et al. Outpatient chemotherapy with gemcitabine and oxaliplatin in patients with biliary tract cancer. $\mathrm{Br}$ $J$ Cancer. 2006;95(7):848-852. doi:10.1038/sj.bjc.6603334

7. Jang JS, Lim HY, Hwang IG, et al. Gemcitabine and oxaliplatin in patients with unresectable biliary cancer including gall bladder cancer: a Korean Cancer Study Group phase II trial. Cancer Chemoth Pharm. 2010;65(4):641-647. doi:10.1007/s00280-009-1069-7

8. Sharma A, Dwary AD, Mohanti BK, et al. Best supportive care compared with chemotherapy for unresectable gall bladder cancer: a randomized controlled study. J Clin Oncol. 2010;28 (30):4581-4586. doi:10.1200/JCO.2010.29.3605

9. Chen JS, Hsu C, Chiang NJ, et al. A KRAS mutation status-stratified randomized phase II trial of gemcitabine and oxaliplatin alone or in combination with cetuximab in advanced biliary tract cancer. Ann Oncol. 2015;26(5):943-949. doi:10.1093/annonc/mdv035

10. Lee J, Park SH, Chang HM, et al. Gemcitabine and oxaliplatin with or without erlotinib in advanced biliary-tract cancer: a multicentre, open-label, randomised, phase 3 study. Lancet Oncol. 2012;13 (2):181-188. doi:10.1016/S1470-2045(11)70301-1 
11. Leone F, Marino D, Cereda S, et al. Panitumumab in combination with gemcitabine and oxaliplatin does not prolong survival in wild-type KRAS advanced biliary tract cancer: a randomized phase 2 trial (Vecti-BIL study). Cancer. 2016;122(4):574-581. doi:10.1002/cncr.29778

12. Malka D, Cervera P, Foulon S, et al. Gemcitabine and oxaliplatin with or without cetuximab in advanced biliary-tract cancer (BINGO): a randomised, open-label, non-comparative phase 2 trial. Lancet Oncol. 2014;15(8):819-828. doi:10.1016/S1470-2045(14)70212-8

13. Morizane C, Okusaka T, Mizusawa J, et al. Combination gemcitabine plus S-1 versus gemcitabine plus cisplatin for advanced/recurrent biliary tract cancer: the FUGA-BT (JCOG1113) randomized phase III clinical trial. Ann Oncol. 2019;30(12):1950-1958. doi:10.1093/annonc/mdz402

14. Sakai D, Kanai M, Kobayashi S, et al. 615ORandomized phase III study of gemcitabine, cisplatin plus S-1 (GCS) versus gemcitabine, cisplatin (GC) for advanced biliary tract cancer (KHBO1401-MITSUBA). Ann Oncol. 2018;29:viii205. doi:10.1093/annonc/mdy282

15. Siebenhüner AR, Seifert H, Bachmann H, et al. Adjuvant treatment of resectable biliary tract cancer with cisplatin plus gemcitabine: a prospective single center phase II study. BMC Cancer. 2018;18 (1):72. doi:10.1186/s12885-017-3967-0

16. Ebata T, Hirano S, Konishi M, et al. Randomized clinical trial of adjuvant gemcitabine chemotherapy versus observation in resected bile duct cancer. Br J Surg. 2018;105(3):192-202. doi:10.1002/bjs.10776

17. Edeline J, Benabdelghani M, Bertaut A, et al. Gemcitabine and oxaliplatin chemotherapy or surveillance in resected biliary tract cancer (PRODIGE 12-ACCORD 18-UNICANCER GI): a randomized phase III study. J Clin Oncol. 2019;37(8):658-667. doi: $10.1200 /$ JCO.18.00050

18. Primrose JN, Fox RP, Palmer DH, et al. Capecitabine compared with observation in resected biliary tract cancer (BILCAP): a randomized, controlled, multicentre, phase 3 study. Lancet Oncol. 2019;20 (5):663-673. doi:10.1016/S1470-2045(18)30915-X

19. Kobayashi S, Nagano H, Tomokuni A, et al. A prospective, randomized phase II study of adjuvant gemcitabine versus S-1 after major hepatectomy for biliary tract cancer (KHBO 1208): Kansai Hepato-Biliary Oncology Group. Ann Surg. 2019;270(2):230-237. doi:10.1097/SLA.0000000000002865

20. Stein A, Arnold D, Bridgewater J, et al. Adjuvant chemotherapy with gemcitabine and cisplatin compared to observation after curative intent resection of cholangiocarcinoma and muscle invasive gallbladder carcinoma (ACTICCA-1 trial) - a randomized, multidisciplinary, multinational phase III trial. BMC Cancer. 2015;15:564. doi:10.1186/ s12885-015-1498-0

21. Murakami Y, Uemura K, Sudo T, et al. Prognostic factors of patients with advanced gallbladder carcinoma following aggressive surgical resection. J Gastrointest Surg. 2011;15(6):1007-1016. doi:10.1007/ s11605-011-1479-9
22. Takada T, Amano H, Yasuda $H$, et al. Is postoperative adjuvant chemotherapy useful for gallbladder carcinoma? A phase III multicenter prospective randomized controlled trial in patients with resected pancreaticobiliary carcinoma. Cancer. 2002;95 (8):1685-1695. doi:10.1002/cncr.10831

23. Shroff RT, Kennedy EB, Bachini M, et al. Adjuvant therapy for resected biliary tract cancer: ASCO clinical practice guideline. J Clin Oncol. 2019;37(12):1015-1027. doi:10.1200/JCO.18.02178

24. André T, Louvet C, Artru P, et al. A phase II study of gemcitabine and oxaliplatin (gemox) in advanced biliary adenocarcinoma (ABA). Preliminary results. Eur J Cancer. 2001;37:S19. doi:10.1016/S09598049(01)80552-9

25. André T, Tournigand C, Rosmorduc O, et al. Gemcitabine combined with oxaliplatin (GEMOX) in advanced biliary tract adenocarcinoma: a GERCOR study. Ann Oncol. 2004;15(9):1339-1343. doi:10.1093/ annonc/mdh351

26. Cho M, Wang-Gillam A, Myerson R, et al. A phase II study of adjuvant gemcitabine plus docetaxel followed by concurrent chemoradation in resected pancreaticobiliary carcinoma. HPB. 2015;17 (7):587-593. doi:10.1111/hpb.12413

27. Kainuma O, Miura F, Furukawa D, et al. Feasibility and efficacy of gemcitabine plus cisplatin combination therapy after curative resection for biliary tract cancer. J Hepato-Bil-Pan Sci. 2015;22 (11):789-794.

28. Toyoda M, Ajiki T, Fujiwara Y, et al. Phase I study of adjuvant chemotherapy with gemcitabine plus cisplatin in patients with biliary tract cancer undergoing curative resection without major hepatectomy (KHBO1004). Cancer Chemoth Pharma. 2014;73(6):1295-1301. doi:10.1007/s00280-014-2431-y

29. Eckel F, Brunner T, Jelic S. Biliary cancer: ESMO clinical practice guidelines for diagnosis, treatment and follow-up. Ann Oncol. 2010;21(Suppl 5):v65-9. doi:10.1093/annonc/mdq167

30. Li Y, Zhou Y, Hong Y, et al. The efficacy of different chemotherapy regimens for advanced biliary tract cancer: a systematic review and network meta-analysis. Front Oncol. 2019;9:441. doi:10.3389/ fonc. 2019.00441

31. Valle JW, Lamarca A, Goyal L, Barriuso J, Zhu AX. New horizons for precision medicine in biliary tract cancers. Cancer Discov. 2017;7 (9):943-962. doi:10.1158/2159-8290.CD-17-0245

32. Woo SM, Lee WJ, Han SS, et al. Capecitabine plus cisplatin as first-line chemotherapy for advanced biliary tract cancer: a retrospective single-center study. Chemotherapy. 2012;58 (3):225-232. doi:10.1159/000339499

\section{Publish your work in this journal}

Cancer Management and Research is an international, peer-reviewed open access journal focusing on cancer research and the optimal use of preventative and integrated treatment interventions to achieve improved outcomes, enhanced survival and quality of life for the cancer patient.
The manuscript management system is completely online and includes a very quick and fair peer-review system, which is all easy to use. Visit http://www.dovepress.com/testimonials.php to read real quotes from published authors. 